\title{
A Clinical Study to Evaluate the Preventive Aspect of Amalaki Swarasa and Haridra Churna with Madhu in Pre-diabetes (Borderline Type2 DM)
}

\author{
Swathi. M. Somayaji \\ Assistant Professor, Department of Swasthavritta, Sushrutha Ayurvedic Medical College and Hospital, \\ Bengaluru
}

\begin{abstract}
Diabetes mellitus is rising to an alarming epidemic level. Pre-diabetes (intermediate hyperglycemia) is a high-risk state for diabetes that is defined by glycemic variables that are higher than normal, but lower than diabetes thresholds. It stems up in persons who are physically inactive, obese, takes more kaphakara medokara abhishyandi ahara. Diabetes if not treated can cause a severe burden on society. The rising prevalence is closely associated with urbanization because of increasing obesity and inclination towards fast food.

For pre-diabetic individuals, lifestyle modification is the cornerstone of diabetes prevention. Physical activity and decreased calorie intake can reduce the occurrence of Diabetes. So an attempt was made to find out the efficacy of Amalaki swarasa and haridra churna with madhu in pre-diabetes (borderline diabetes)
\end{abstract}

Keywords: Pre-Diabetes, Amalaki, Haridra, Madhu, Borderline Diabetes Mellitus

\section{INTRODUCTION}

Diabetes mellitus is a chronic metabolic disorder characterized by hyperglycemia with or without glycosuria, resulting from an absolute or relative deficiency of insulin. ${ }^{1}$

Diabetes is a chronic disease that affects millions of people worldwide. It is a fast growing global problem with huge social, health and economic consequences. The proportion of people with type-2 diabetes is increasing in most countries. $79 \%$ of adults with diabetes were living in low and middle income countries. And it is not a great thing to know that 1 in 2 (212 million) people with diabetes were undiagnosed. 352 million people were at risk of developing type-2 diabetes. ${ }^{2}$

In most cases, blood glucose levels in persons with diabetes increase with age, leading to heart disease, stroke, chronic kidney failure, foot ulcers, damage to the eyes. Such high glucose levels are associated with frequent urination and increased thirst and hunger. ${ }^{3}$

There are many factors associated with the onset of diabetes, some of which are modifiable. Modifiable factors in persons, who are pre-diabetic, regardless of their age, are a diet high in fat and low in fresh fruits vegetables and whole grains. Foods containing low levels of sugar may also prevent and/or delays diabetes onset. In addition, the maintenance of normal cholesterol and blood pressure levels may also reduce pre-diabetes symptoms and diabetes onset. $^{4}$

Pre-diabetes is a health condition that means blood sugar level is higher than normal, but not yet high enough to be diagnosed with diabetes. Pre-diabetes usually has no symptoms, but it almost always shows up before it is diagnosed. About 86 million people in US over age 20 
have pre-diabetes. Although most people with pre-diabetes have no symptoms but one might notice feeling of thirsty, increasing frequency of micturition, fatigue, blurry vision.

Risk factors and cause of prediabetes are persons with gestational diabetes, PCOS, over-weight /obese especially around the middle (belly fat) have high cholesterol, high LDL cholesterol, lack of exercise and age above 40 years..$^{5}$

India would have the certainty of becoming the capital of 3 major diseases by 2030,viz.,Diabetes, TB and AIDS. The gravity of the problem is understood by the fact that every 5th patient visiting a physician is diabetic and every 5 th diabetic in the world is Indian ${ }^{6}$.

In classics, various pathya dravyas are explained in the context of prameha. Among those, amalaki, haridra and madhu are famous for its anti-diabetic effects. These are cost effective and easily available. Usage of Amalaki (Emblica officinalis), commonly known as Indian gooseberry possess anti-diabetic effects through their anti oxidant and free radical scavenging properties.

Haridra (curcuma longa. rhizomes) with the most active component curcumin is a potential therapeutic agent in diabetes because of its effect in reducing glycemia. Anti diabetic drugs in combination with honey improve glycemic control, enhance anti oxidant defences and reduce oxidative damage. These effects are believed to be mediated partly via antioxidant mechanism of honey. 7Hence a hypothesis is made to evaluate the effect of amalaki swarasa with haridra and madhu as preventive measure in management of borderline DM (Pre-diabetic condition).

Therefore keeping the above points in view the present clinical study is planned, to evaluate the "A clinical study to evaluate the preventive aspect of Amalaki swarasa and haridra churna with Madhu in Prediabetic condition (borderline type-2 DM)" Amalaki, haridra and madhu are said to be best pathya dravyas in prameha. It was proposed to take the persons having FBS between 100-120 mg/dl which are designated as pre-diabetic who if not managed properly will turn into TYPE 2 Diabetics. This study helps to evaluate the effect of Amalaki swarasa and haridra churna with madhu in controlling the pre diabetes and preventing diabetes.

In present study 15 subjects of Prediabetes were administered Amalaki swarasa with haridra and madhu in the early morning, empty stomach for two months. After completing the study the procured statistical data was tested with different statistical methods, which shown statistically significant results in all criteria. Over all Amalaki swarasa and haridra churna with madhu has shown Mild improvement in patients of Pre-diabetes.

\section{MATERIALS AND METHODS OBJECTIVES OF THE STUDY}

1) To study the effect of Amalaki swarasa and haridra churna with madhu in patients of pre- diabetes stage.

2) To observe if there is any benefits after the use of this combination.

\section{SOURCE OF DATA}

Patients from OPD, IPD and camps were selected for this study.

\section{METHOD OF COLLECTION OF DATA}

30 patients who were fulfilling the criteria for diagnosis and inclusion were Selected irrespective of sex, occupation, religion etc for the present clinical study.

\section{DIAGNOSTIC CRITERIA:}

Diagnosis were established on the basis of symptoms seen in the Patients, history and laboratory investigations.

Table No. 1 Grading Table for symptoms

\begin{tabular}{|l|l|l|l|l|}
\hline & Grade '0' & Grade '1' & Grade '2' & Grade '3' \\
\hline INCREASED HUNGER & Normal & Mildly Increased & Moderately increased & Severely increased \\
\hline URINATION & 3-5 Times in a day & 5-7 Times in a day & 7- 10 Times in a day & More than 10 Times in a day \\
& 0-1 Time at night & 2-3 Time at night & 3-5 Time at night & More than 5 Times at night \\
\hline FATIGUE & Absent & Mild & Moderate & Severe \\
\hline INCREASED THIRST & Absent & Mild & Moderate & Severe \\
\hline
\end{tabular}




\section{LABORATORY INVESTIGATIONS:}

1) FASTING PLASMA GLUCOSE TEST (FPG)

Normal - Less than $100 \mathrm{mg} / \mathrm{dl}$

Pre-diabetes - Between 100 and $125 \mathrm{mg} / \mathrm{dl}$

Diabetes - Greater than 126

2) Random value

$200 \mathrm{mg} / \mathrm{dl}(11.1 \mathrm{mmol} / \mathrm{L})$ or more

In a symptomatic patient DM

\section{INCLUSION CRITERIA}

- Subjects were selected respective sex

- Subjects aged 40 to 60 years of age

- Subjects with family history of type2 DM and high bp

- Subjects with sedentary lifestyle

- Obese (BMI more than 30)

- Clinical signs and symptoms fulfilling the criteria of pre diabetes

- Patients having impaired fasting glucose(IFG-100mg/dl-125 mg/dl)

\section{EXCLUSION CRITERIA}

- subjects with other systemic disease (HTN/IHD) etc

- Subjects aged less than 40 and more than 60 years

- Subjects suffering from type 1 DM

- Subjects suffering from type $2 \mathrm{DM}$

- Patients on steroids or oral hypoglycemic drugs

\section{STUDY GROUPS:}

It was a clinical study with two groups, each group comprising of 15 patients.

GROUP A - Patients were advised to take amalaki swarasa and haridra churna with madhu once a day for 60 days

GROUP B - Patients were not advised anything and kept under observation for 60 days.

Assessment was done after 2 months.

Blood investigation and symptoms were noted for every 15 days.

\section{ADMINISTRATION OF MEDICINE}

Amalaki was made into swarasa (fresh juice) and haridra was crushed and made into powder manually. Amalaki (25ml), Haridra(2gm) and Madhu (10gm) was consumed in an empty stomach, once a day.

\section{Statistical Analysis:}

All the observation made on various parameters of both the groups were noted

And the data was analyzed by Friedman's test, Wilcoxon signed rank test, unpaired ' $t$ ' test to calculate data between two groups and the result of Statistical analysis was interpreted in terms of mean (x) S.D., S.E and P value.

The obtained results were interpreted in the statistically terms as

- Significant: $\mathrm{P}<0.05 / \mathrm{P}<0.01$

- Highly Significant: $\mathrm{P}<0.001$

\section{ASSESSMENT CRITERIA:}

A Self formulated scoring scale was used to assess the symptoms.

- Subjective criteria

- Increased thirst

a. Normal hunger \& also satiety achieved 0

b. Hunger is more, mild satiety -1

c. Severe hunger, moderate satiety, nibbling present -2

d. Very severe hunger, reach to satiety too late, extensive eating seen -3

- Increased hunger

a) Normal thirst - 0

b) Upto 2 litres of excess intake of fluids 1

c) Upto 2-3 litres of excess intake of fluids $-2$

d) More than 3 litres of excess intake of fluids -3

- Fatigue

a) No fatigue, performs work normally - 0

b) Mild Fatigue but can perform work - 1

c) Moderate fatigue which impairs work occasionally -2 
d) Severe fatigue and Cant perform any work -3

- Frequent urination

a) 3-5 Times in a day and 0-1 Times at night

b) 5-7 Times in a day and 2-3 Times at night c) 7-10 Times in a day and 3-5 Times at night

d) More than 10 Times in a day and More than 5 Times at night

- Objective criteria

i. RBS

ii. FBS

iii. $\quad$ PPBS

\section{EVALUATION TABLE FOR THE TREATMENT}

Table No. 2 Subjective Parameters of Group A / Group B

\begin{tabular}{|l|l|l|l|l|l|}
\hline VARIABLES & BEFORE TREATMENT & ON 15 ${ }^{\mathrm{TH}}$ DAY & ON 30 $^{\mathrm{TH}}$ DAY & ON 45 $^{\mathrm{TH}}$ DAY & ON 60 $^{\mathrm{TH}}$ DAY \\
\hline INCREASED APPETITE & & & & & \\
\hline FREQUENT URINATION & & & & & \\
\hline FATIGUE & & & & & \\
\hline INCREASED THIRST & & & & & \\
\end{tabular}

Table No. 3 Objective Parameters of Group A / Group B

\begin{tabular}{|l|l|l|l|l|l|}
\hline VARIABLES & BEFORE TREATMENT & ON 15 & DAY & ON 30 $^{\mathrm{TH}}$ DAY & ON 45 \\
\hline FBS & & & & & \\
\hline PPBS & & & & & \\
\hline RBS & & & & & \\
\hline
\end{tabular}

\section{FOLLOW UP STUDY:}

The patients were advised to report for the follow up twice in a month (every 15 days) for two months.

\section{Statistical analysis}

Statistical results of in Group A patients (administered with medicine) and Group B patients in (without any medical intervention) before and after treatment

Total 30 patients were registered in this study. Out of that all 30 patients were studied in this project. 15 patients were in group A while 15 were in B group. Each patient was observed thoroughly and noted neatly. The observations are recorded and necessary charts and graphs were made

\section{OBSERVATION \& RESULTS Results on subjective parameters}

In this work of 15 patients studied with Group-A Increased Thirst revealed are given in detail in Table No.4. Statistical analysis showed that the mean score which was 3.5 before the treatment was reduced to 2.23 after the treatment with $36.28 \%$ improvement and there is a statistically significant. $(\mathrm{P}<0.05)$ results are graphically represented in graph no. 17

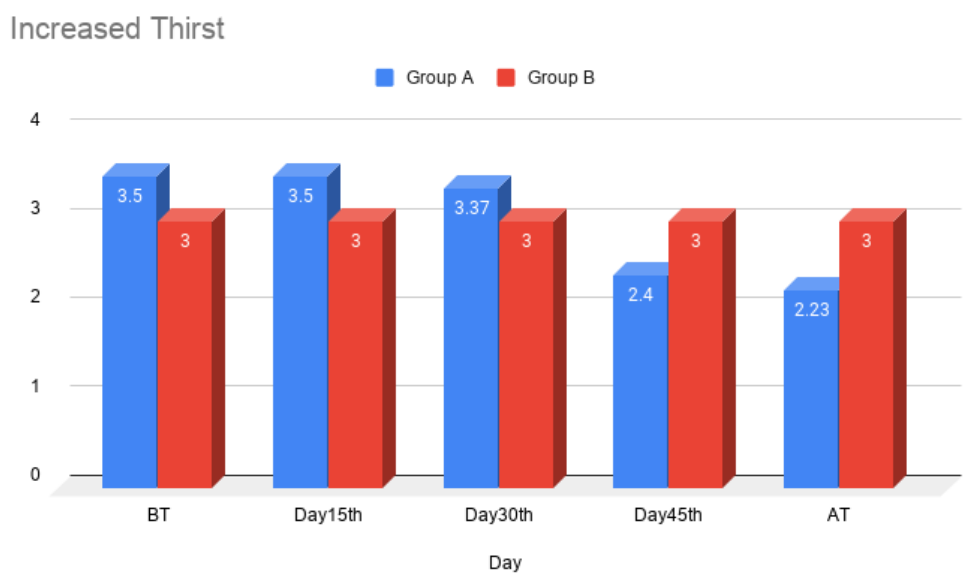

Graph No.1: Effect of Group A \& Group B on Increased thirst of Type2 DM 
In this work of 15 patients studied with Group-B Increased Thirst revealed are given in detail in Table No.4. Statistical analysis showed that the mean score which was 3 before the treatment and has remained same 3 after the treatment with $0 \%$ improvement. Results are graphically represented in Graph no. 1

Table No. 4 Mean of Increased thirst

\begin{tabular}{|l|l|l|}
\hline Increased Thirst & \multicolumn{2}{|l|}{} \\
\hline Day & Group A & Group B \\
\hline BT & 3.5 & 3 \\
\hline Day15th & 3.5 & 3 \\
\hline Day30th & 3.37 & 3 \\
\hline Day45th & 2.4 & 3 \\
\hline AT & 2.23 & 3 \\
\hline
\end{tabular}

Increased Hunger:

Results on subjective parameters for increased hunger

In this work of 15 patients studied with Group-A Increased Hunger revealed are given in detail in Table No.4. Statistical analysis showed that the mean score which was 3.53 before the treatment was reduced to 2.13 after the treatment with $39.66 \%$ improvement and there is a statistically significant. $(\mathrm{P}<0.05)$ results are graphically represented in graph no 2:

In this work of 15 patients studied with Group-B Increased Hunger revealed are given in detail in Table No.4. Statistical analysis showed that the mean score which was 2.9 before the treatment and has increased to 3.07 after the treatment with $5.86 \%$ decrement. Results are graphically represented in graph no 2:

Table No.5 Mean of Increased hunger

\begin{tabular}{|l|l|l|}
\hline \multicolumn{2}{|l|}{ Increased Hunger } \\
\hline Day & Mean score of Group A & Mean score of Group B \\
\hline BT & 3.53 & 2.9 \\
\hline Day15th & 3.53 & 2.9 \\
\hline Day30th & 3.13 & 3.07 \\
\hline Day45th & 2.67 & 3.07 \\
\hline AT & 2.13 & 3.07 \\
\hline
\end{tabular}

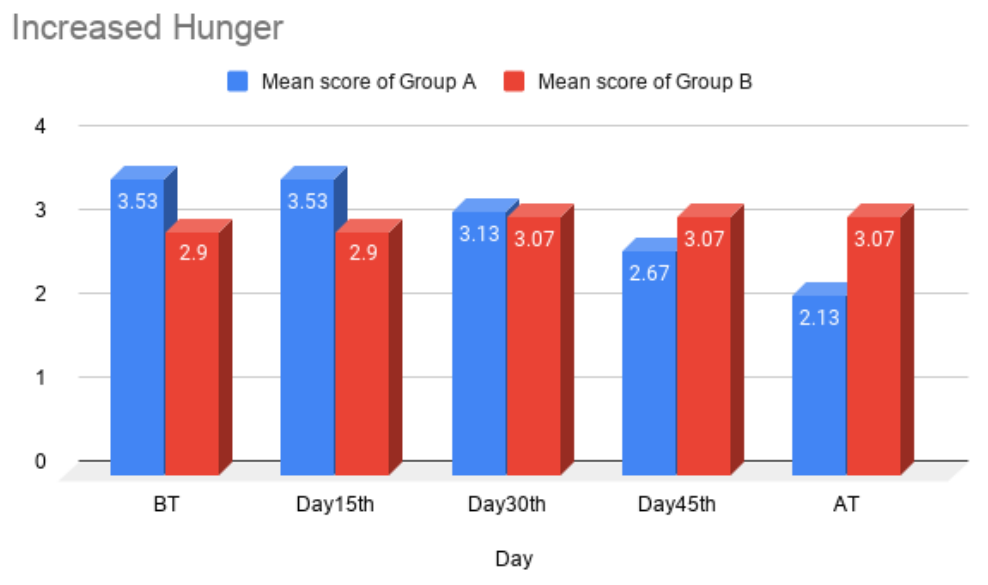

Graph No.2: Effect of Group A \& Group B on Increased Hunger of Type2 DM

\section{Results of subjective parameters on fatigue}

In this work of 15 patients studied with Group-A Fatigue revealed are given in detail in Table No.6. Statistical analysis showed that the mean score which was 3.9 before the treatment was reduced to 1.57 after the treatment with $59.74 \%$ improvement and there is a statistically significant. $(\mathrm{P}<0.05)$ results are graphically represented in graph no 19:

In this work of 15 patients studied with Group-B Fatigue revealed are given in detail in Table No.6. Statistical analysis showed that the mean score which was 2.7 before the treatment and has increased to 3.2 after the treatment with $18.5 \%$ decrement. Results are graphically represented in graph no 3:

Table No.6: Mean For fatigue

\begin{tabular}{|l|l|l|}
\hline Fatigue & \multicolumn{2}{|c|}{} \\
\hline Day & Mean score of Group A & Mean score of Group B \\
\hline BT & 3.9 & 2.7 \\
\hline Day15th & 3.9 & 2.87 \\
\hline Day30th & 3.07 & 3.03 \\
\hline Day45th & 2.57 & 3.2 \\
\hline AT & 1.57 & 3.2 \\
\hline
\end{tabular}




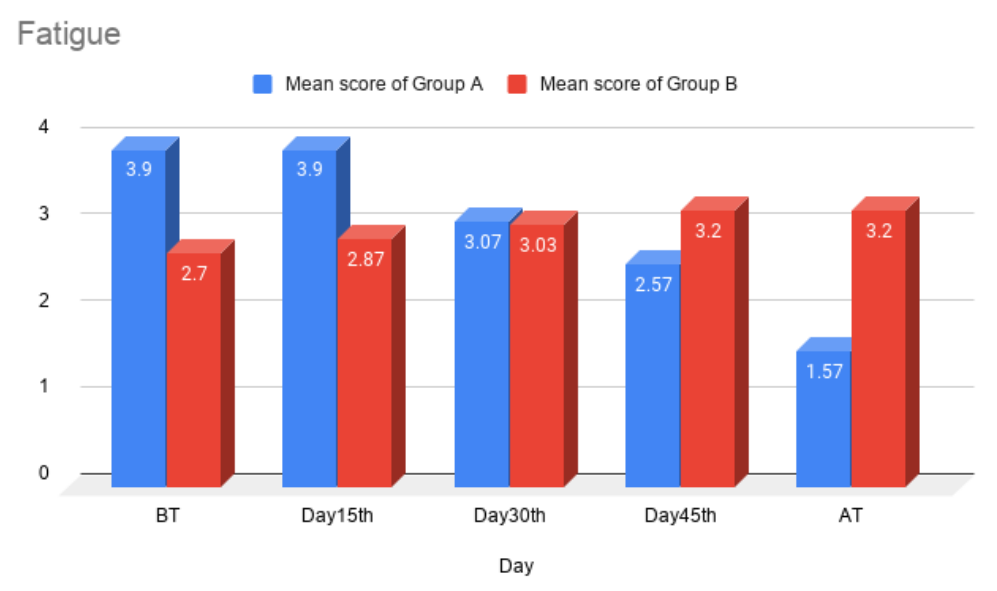

Graph No.3: Effect of Group A and Group B on fatigue of Type2 DM

Results of Subjective Parameters for
Frequency of urination

In this work of 15 patients studied with Group-A Frequency Of Urination revealed are given in detail in Table No.7. Statistical analysis showed that the mean score which was 3.47 before the treatment was reduced to 2.23 after the treatment with $35.73 \%$ improvement and it is statistically significant. $(\mathrm{P}<0.05)$ results are graphically represented in graph no 20:

In this work of 15 patients studied with Group-B Increased Thirst revealed are given in detail in Table No.7. Statistical analysis showed that the mean score which was 3 before the treatment and has remained same 3 after the treatment with $0 \%$ improvement. Results are graphically represented in graph no 4:

Table No.7 Mean for Frequency of Urination

\begin{tabular}{|l|l|l|}
\hline \multicolumn{3}{|l|}{ Frequency Of Urination } \\
\hline Day & Mean score of Group A & Mean score of Group B \\
\hline BT & 3.47 & 3 \\
\hline Day15th & 3.47 & 3 \\
\hline Day30th & 3.33 & 3 \\
\hline Day45th & 2.5 & 3 \\
\hline AT & 2.23 & 3 \\
\hline
\end{tabular}

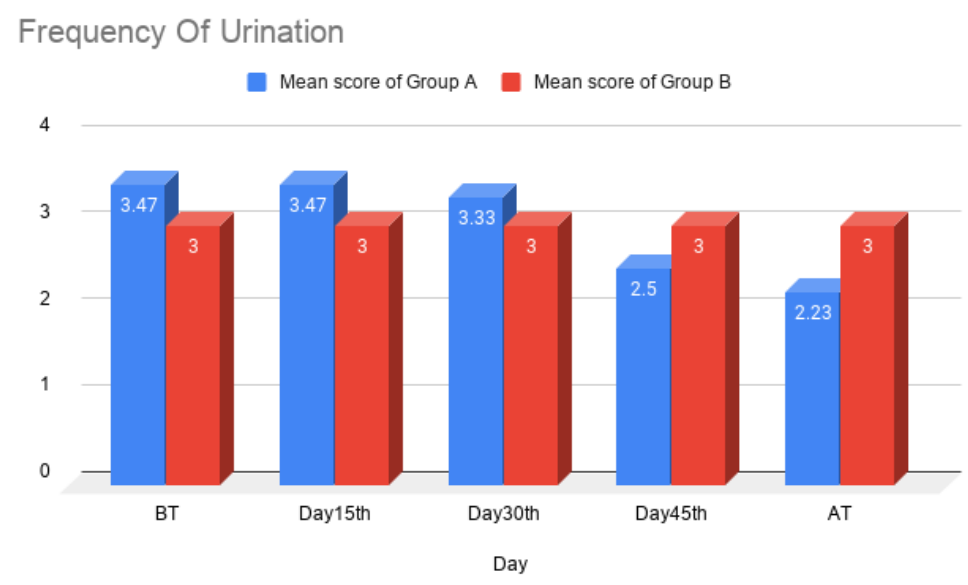

Graph No.4: Effect of Group A and Group B on frequency of urination of Type2 DM

\section{Effect of Group-A and B on FBS}

Table No 8 Group Statistics FBS

\begin{tabular}{|l|l|l|l|l|l|}
\hline \multicolumn{6}{|c|}{ Group Statistics FBS } \\
\hline & Group & $\mathbf{N}$ & Mean & Std. Deviation & Std. Error Mean \\
\hline \multirow{2}{*}{ BT } & Group A & 15 & 122.2 & 12.852 & 3.318 \\
\cline { 2 - 6 } & Group B & 15 & 122.93 & 7.146 & 1.845 \\
\hline Day15th & Group A & 15 & 121.4 & 12.397 & 3.201 \\
\cline { 2 - 6 } & Group B & 15 & 124 & 6.866 & 1.773 \\
\hline Day30th & Group A & 15 & 119.2 & 10.995 & 2.839 \\
\cline { 2 - 6 } & Group B & 15 & 124.13 & 7.511 & 1.939 \\
\hline
\end{tabular}




\begin{tabular}{|l|l|l|l|l|l|}
\hline \multicolumn{7}{|c|}{ Table 8 continued... } \\
\hline \multirow{2}{*}{ Day45th } & Group A & 15 & 117.33 & 10.887 & 2.811 \\
\cline { 2 - 6 } & Group B & 15 & 123.67 & 7.724 & 1.994 \\
\hline \multirow{2}{*}{ AT } & Group A & 15 & 114.2 & 9.966 & 2.573 \\
\cline { 2 - 6 } & Group B & 15 & 123.93 & 6.85 & 1.769 \\
\hline
\end{tabular}

\section{Effect on FBS}

In this work of 15 patients studied with Group-A FBS revealed are given in detail in Table No.8. Statistical analysis showed that the mean score which was 122.2 before the treatment was reduced to 114.2 after the treatment with $6.5 \%$ changes and there is statistically significant. $(\mathrm{P}<0.05)$ results are graphically represented in graph no 21:

In this work of 15 patients studied with Group-B FBS revealed are given in detail in Table No.8. Statistical analysis showed that the mean score which was
122.93 before the treatment was reduced to 123.93 after the treatment with decrement of $0.81 \%$ and results are graphically represented in graph no 21:

Table No. 9 Percentage change in FBS

\begin{tabular}{|l|l|l|l|l|}
\hline FBS & $\begin{array}{l}\text { Group } \\
\text { Day }\end{array}$ & $\begin{array}{l}\text { Group } \\
\text { B }\end{array}$ & $\begin{array}{l}\text { Percentage } \\
\text { Change in } \\
\text { FBS BT and } \\
\text { AT in Group } \\
\text { A }\end{array}$ & $\begin{array}{l}\text { Percentage } \\
\text { Change in } \\
\text { FBS BT and } \\
\text { AT in Group } \\
\text { B }\end{array}$ \\
\hline BT & 122.2 & 122.93 & 6.55 & -0.81 \\
\hline Day15th & 121.4 & 124 & & \\
\hline Day30th & 119.2 & 124.13 & & \\
\hline Day45th & 117.33 & 123.67 & & \\
\hline AT & 114.2 & 123.93 & & \\
\hline
\end{tabular}

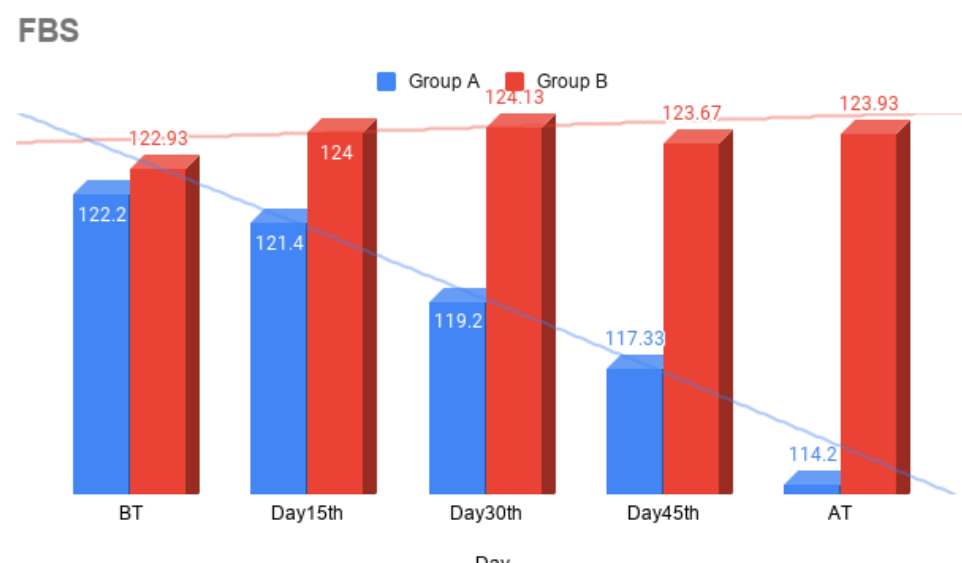

Graph 5: Effect of Group A \& Group B on FBS

\section{Effect on PPBS}

Table No. 10 Group Statistics PPBS

\begin{tabular}{|l|l|l|l|l|l|}
\hline \multicolumn{6}{|c|}{ Group Statistics PPBS } \\
\hline & Group & $\mathbf{N}$ & Mean & Std. Deviation & Std. Error Mean \\
\hline BT & Group A & 15 & 170.33 & 10.111 & 2.611 \\
\cline { 2 - 6 } & Group B & 15 & 169.47 & 7.954 & 2.054 \\
\hline Day15th & Group A & 15 & 169.73 & 9.362 & 2.417 \\
\cline { 2 - 6 } & Group B & 15 & 170.73 & 7.869 & 2.032 \\
\hline Day30th & Group A & 15 & 167.47 & 8.114 & 2.095 \\
\cline { 2 - 6 } & Group B & 15 & 170.13 & 7.745 & 2 \\
\hline Day45th & Group A & 15 & 164.93 & 7.815 & 2.018 \\
\cline { 2 - 6 } & Group B & 15 & 169.53 & 7.864 & 2.03 \\
\hline AT & Group A & 15 & 162.13 & 7.708 & 1.99 \\
\cline { 2 - 6 } & Group B & 15 & 170.07 & 7.62 & 1.968 \\
\hline
\end{tabular}

Table 11: Percentage Change in PPBS

\begin{tabular}{|l|l|l|l|l|}
\hline PPBS & Group A & Group B & $\begin{array}{l}\text { Percentage Change in PPBS BT and AT } \\
\text { in Group A }\end{array}$ & $\begin{array}{l}\text { Percentage Change in PPBS BT and AT } \\
\text { in Group B }\end{array}$ \\
\hline Day & 170.33 & 169.47 & \multirow{2}{*}{4.81} & -0.35 \\
\cline { 1 - 3 } Day15th & 169.73 & 170.73 & & \\
\hline Day30th & 167.47 & 170.13 & & \\
\hline Day45th & 164.93 & 169.53 & & \\
\hline AT & 162.13 & 170.07 & & \\
\hline
\end{tabular}




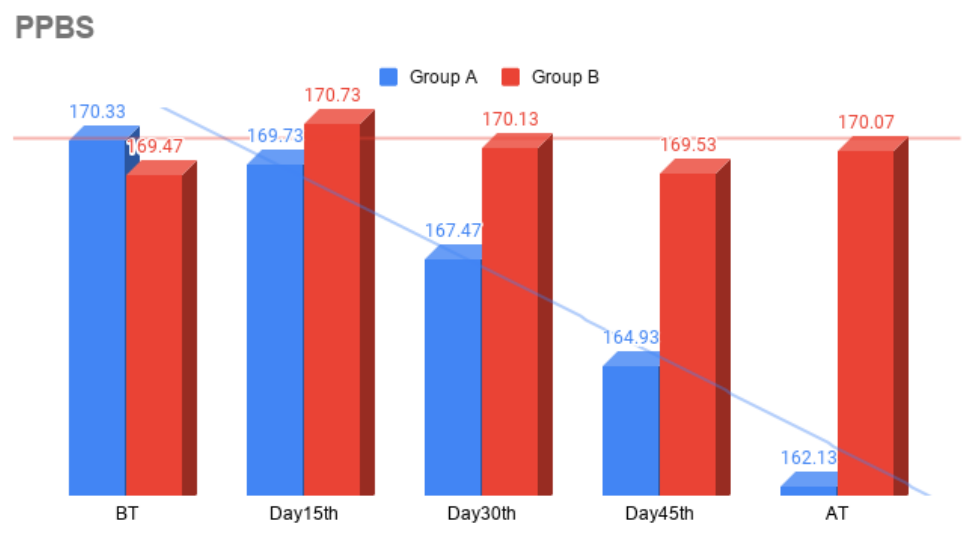

Day

Graph No.6: Effect of Group A and Group B on PPBS of Type2 DM

\section{Effect on PPBS}

In this work of 15 patients studied with Group-PPBS revealed are given in detail in Table No.11. Statistical analysis showed that the mean score which was 177.33 before the treatment was reduced to 162.13 after the treatment with $4.81 \%$ changes and there is statistically significant. $(\mathrm{P}<0.05)$ results are graphically represented in graph no 22:
In this work of 15 patients studied in with Group-B PPBS revealed are given in detail in Table No.11. Statistical analysis showed that the mean score which was 169.47 before the treatment was increased to 170.07 after the treatment with decrement of $0.35 \%$ and results are graphically represented in graph no 6 .

\section{Effect on RBS}

Table No. 12 Reading on RBS

\begin{tabular}{|l|l|l|l|l|l|}
\hline Group Statistics RBS & Table No. 12 Reading on RBS \\
\hline Day Of Treatment & Group & N & Mean & Std. Deviation & Std. Error Mean \\
\hline \multirow{3}{*}{ BT } & Group A & 15 & 154.6 & 17.05 & 4.402 \\
\cline { 2 - 7 } & Group B & 15 & 154.53 & 14.956 & 3.862 \\
\hline \multirow{2}{*}{ Day15th } & Group A & 15 & 154 & 16.553 & 4.274 \\
\cline { 2 - 7 } & Group B & 15 & 156 & 14.745 & 3.807 \\
\hline Day30th & Group A & 15 & 151.07 & 14.24 & 3.677 \\
\cline { 2 - 7 } & Group B & 15 & 156.2 & 15.162 & 3.915 \\
\hline Day45th & Group A & 15 & 148.53 & 12.58 & 3.248 \\
\cline { 2 - 6 } & Group B & 15 & 155.8 & 15.753 & 4.068 \\
\hline AT & Group A & 15 & 144.87 & 11.338 & 2.927 \\
\cline { 2 - 6 } & Group B & 15 & 155.87 & 15.454 & 3.99 \\
\hline
\end{tabular}

RBS

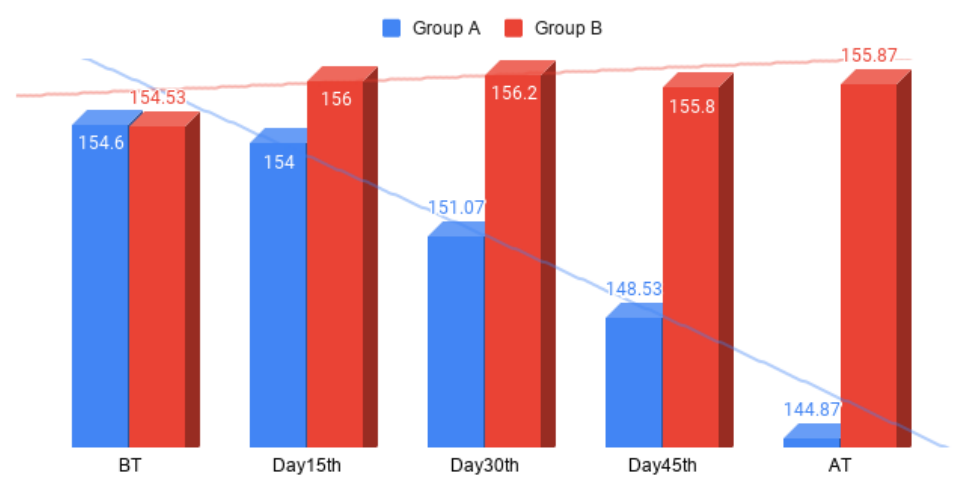

Day

Graph No.7: Effect of Group A and Group B on RBS of Type2 DM 
Table No. 13 Percentage Change in RBS

\begin{tabular}{|c|c|c|c|c|}
\hline \multicolumn{5}{|l|}{ RBS } \\
\hline Day & $\begin{array}{l}\text { Group } \\
\text { A }\end{array}$ & $\begin{array}{l}\text { Group } \\
\text { B }\end{array}$ & $\begin{array}{l}\text { Percentage Change in RBS BT and AT in } \\
\text { Group A }\end{array}$ & $\begin{array}{l}\text { Percentage Change in RBS BT and AT in } \\
\text { Group B }\end{array}$ \\
\hline BT & 154.6 & 154.53 & 6.29 & -0.87 \\
\hline Day15th & 154 & 156 & & \\
\hline Day30th & 151.07 & 156.2 & & \\
\hline Day45th & 148.53 & 155.8 & & \\
\hline AT & 144.87 & 155.87 & & \\
\hline
\end{tabular}

In this work of 15 patients studied with Group-A RBS revealed are given in detail in Table No.13. Statistical analysis showed that the mean score which was 154.6 before the treatment was reduced to 144.87 after the treatment with $6.29 \%$ changes and there is statistically significant. $(\mathrm{P}<0.05)$ results are graphically represented in graph no 23:

In this work of 15 patients studied in with Group-B RBS revealed are given in detail in Table No.13. Statistical analysis showed that the mean score which was 154.53 before the treatment was increased to 155.87 after the treatment with decrement of $0.87 \%$ and results are graphically represented in graph no 7 :

Table No. 14 Percentage Change and Overall Improvement in Group A w.r.t Symptoms:

\begin{tabular}{|l|l|l|l|}
\hline Symptoms & BT/AT & $\begin{array}{l}\text { Mean Score of } \\
\text { Group A }\end{array}$ & $\begin{array}{l}\text { Percentage } \\
\text { Change }\end{array}$ \\
\hline \multirow{2}{*}{$\begin{array}{l}\text { Increased } \\
\text { Hunger }\end{array}$} & $\mathrm{BT}$ & 3.5 & \multirow{3}{*}{36.28} \\
\cline { 2 - 3 } & $\mathrm{AT}$ & 2.23 & \\
\hline Increased Thirst & $\mathrm{BT}$ & 3.53 & \multirow{3}{*}{59.66} \\
\cline { 2 - 3 } & $\mathrm{AT}$ & 2.13 & \multirow{3}{*}{39.8} \\
\hline \multirow{2}{*}{ Fatigue } & $\mathrm{BT}$ & 3.9 & \\
\cline { 2 - 3 } & $\mathrm{AT}$ & 1.57 & \\
\hline \multirow{2}{*}{$\begin{array}{l}\text { Frequency } \\
\text { Urination }\end{array}$} & $\mathrm{BT}$ & 3.47 & \\
\cline { 2 - 3 } & $\mathrm{AT}$ & 2.23 & \\
\hline
\end{tabular}

The percentage of improvement for Increased Hunger in Group A is $36.28 \%$, for Increased Thirst is $39.66 \%$, for Fatigue is $59.8 \%$, for Frequency of Urination is 35.73 .

Table No. 15 Percentage Change and Overall Improvement in Group A w.r.t Investigations

\begin{tabular}{|l|l|l|l|}
\hline Investigations & BT/AT & $\begin{array}{l}\text { Mean Score of } \\
\text { Group A }\end{array}$ & $\begin{array}{l}\text { Percentage } \\
\text { Change }\end{array}$ \\
\hline FBS & BT & 122.2 & 6.55 \\
\cline { 2 - 3 } & AT & 114.2 & \\
\hline \multirow{2}{*}{ PPBS } & BT & 170.33 & 4.81 \\
\cline { 2 - 3 } & AT & 162.13 & \\
\hline RBS & BT & 154.53 & 6.25 \\
\cline { 2 - 3 } & AT & 144.87 & \\
\hline
\end{tabular}

The percentage of improvement for FBS in Group A is $6.55 \%$, for PPBS is $4.81 \%$, for RBS is $6.25 \%$.
Table No.16 Overall Improvement in Patients

\begin{tabular}{|c|c|c|c|}
\hline \multicolumn{4}{|c|}{ Overall Improvements } \\
\hline Class & $\begin{array}{l}\text { Improvement } \\
\text { Levels }\end{array}$ & $\begin{array}{l}\text { Number } \quad \text { Of } \\
\text { Patients }\end{array}$ & Percentage \\
\hline $0-25 \%$ & No Improvement & 0 & 0 \\
\hline $25-50 \%$ & Mild Improvement & 6 & 40 \\
\hline $50-75 \%$ & $\begin{array}{l}\text { Moderate } \\
\text { Improvement }\end{array}$ & 7 & 46.7 \\
\hline $\begin{array}{l}75- \\
100 \%\end{array}$ & $\begin{array}{l}\text { Marked } \\
\text { Improvement }\end{array}$ & 2 & 13.3 \\
\hline
\end{tabular}

\section{Overall Improvement}

Mild Improvement Moderate Improvement Marked Improvement

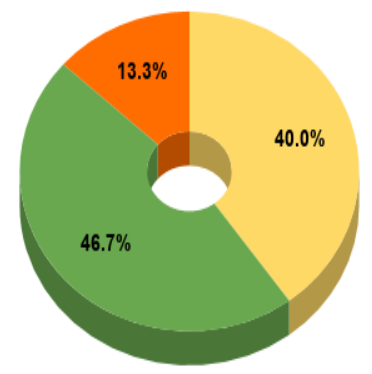

Graph No.8: Overall improvement

\section{DISCUSSION}

Ayurveda doesn't stand simply for the cure of certain disease in individuals. It aims at prevention and promotion of physical and mental health and disease. And preventing diabetes can reduce a lot of burden on society. The combination of Amalaki, haridra along with madhu is said to cure all kinds of prameha. Individual agents are found to be effective in preventing various complications of diabetes. Curcuma longum has been studied for renoprotective, cataract preventing antioxidant, anti-inflammatory, antimicrobial, and anti-carcinogenic activities and Embilica officinalis is rennoprotective, causes insulin release hepatoprotective, gastroprotective, immunomodulator. Different studies demonstrate the hypoglycemic effect of 
honey. Research studies explain to a large extent many medicinal effects of honey such as antioxidant, hepatoprotective, cardio protective, antibacterial, anti-inflammatory, or antitumor.

The present trends of health consciousness, preference of healthy lifestyle and inclination towards usage of herbal medicine, considering simple and cost effective formulation of Amalaki swarasa and haridra churna with madhu can benefit and help in prevention of diabetes.

It is said that nidana parivarjanameva pradhana chikitsa, accordingly the pathya included both dietary and life style modifications which are to be practiced to manage the disease. In dietary pathya, diet rich in fibre content and also qualities opposite to the disease and its components.

Lifestyle modifications include regular exercise to maintain ideal weight. As mentioned in the benefits of vyayama, agnivriddhi, sthaurya, doshakshaya can be attained. Beside regular exercise, manual labour and long distance walking of 100 yojana 100 days i.e., 1 yojana per day, vyayaama,niyuddha, kreeda, gajacharya, turagacharya, rathacharya and padacharya explained.contemporary medicine also suggests to exercise regularly and maintain the ideal weight.

In Madhumeha, apakwa vata and pitta combines with kapha and medas as does dooshana of mootravahi srotas and further does dooshana of basti. Hence produces madhu rasa and madhu varna yukta mootra. It is a santarpana janya vyadhi. Hence the mode of the treatment here should be kaphahara, Medohara, Apatharpanakaraka and Kleda Nashaka.

The combination contains Amalaki, Haridra and Madhu. Amalaki is having Lavana varjita pancha rasa, sheeta virya, Laghu Ruksha guna and Tridoshahara. Haridra is having Katu, Tikta rasa, Laghu Ruksha guna, Ushna virya and Tridoshahara. Madhu is having Katu, Tikta rasa, Laghu Ruksha guna, Ushna virya and mainly kaphahara, lekhana karma.
All the drugs are predominantly of tikta rasa and has laghu ruksha guna. Haridra acts as mutrasangrahaniya, medorogahara and pramehaghna. Amalaki not only acts as prameghna but also as rasayana in madhumeha rogi.it also has the ability to stimulate the islets of langerhans and helps them to secrete their own natural insulin. Thus in diabetic it reduces the blood sugar, imparts a feeling of well being by treating other symptoms further preventing the complications. Madhu with its lekhaniya guna is beneficial in santarpana janya vikara like madhumeha.it also acts as a very good anupana. It serves good amounts of antioxidants, useful to fight minor infections and hence very useful in diabetes.

\section{Increased hunger}

In Group-A, increased hunger after statistical analysis showed that the mean score which was 3.53 before treatment was reduced to 2.13 after treatment with $39.66 \%$ improvement and there is a statistically significant. As the symptom is due to medasavruta agni, the drugs included in the formulation has got medohara properties as well as lekhana properties.

In Group-B increased appetite showed that the mean score which was 2.9 increased to 3.07 on last follow up with $5.86 \%$ decrement and there is a statistically significant $(\mathrm{P}<0.05)$. This indicates that without any medication the severity of the symptoms goes on increasing.

\section{Increased Thirst}

In Group-A statistical analysis on thirst showed that the mean score of which was 3.5 before treatment was reduced to 2.23 after treatment with $36.29 \%$ improvement and there is statistically significant $(\mathrm{P}>0.05)$. The drugs used especially madhu has got thrishnahara and dahaprashamana properties and tikta rasa has got trushnahara properties.

In Group-B increased thirst showed that the mean score which was 3 before treatment remained same after follow up with $0 \%$.improvement. as they have not 
been given with any medication there is no improvement.

\section{Fatigue}

In Group-A fatigue showed that the mean score of which was 3.9 before treatment was reduced to 1.57 after treatment with $59.74 \%$ improvement and there is a statistically significant $(\mathrm{P}<0.05)$. The medicine had good effect on this symptom. This medicine gives a nutritional support which reduces the common symptoms like fatigue, weakness etc.

In Group-B fatigue showed that the mean score if which was 2.7 on $1^{\text {st }}$ follow up was increased to 3.2 on last follow up with $18.52 \%$ decrement.

\section{Frequent urination}

In Group-A frequent urination showed that the mean score which was 3.47 before treatment was reduced to 2.23 after treatment with $35.73 \%$ improvement and there is a statistically significant $(\mathrm{P}<0.05)$. it is due to the drugs have got mootrasangrahaniya properties.

In Group-B frequent urination showed that the mean score which was 3 before remained the same on the last day of follow-up with $0 \%$ improvement.

\section{FBS- Fasting blood sugar}

In Group-A FBS showed that the mean score which was 122.2 before the treatment was reduced to 114.2 after the treatment with $6.55 \%$ changes and there is statistically significant $(\mathrm{P}<0.05)$. The drugs contain potential therapeutic agent which reduces glycemia. Anti-diabetic drugs in combination with honey improve glycemic control further preventing oxidative damage.

In Group-B FBS showed that the mean score which was 122.93 before was increased to 123.93 a with $0.81 \%$ decrement.

\section{PPBS- Post prandial blood sugar}

In Group-A PPBS showed that the mean score which was 177.33 before the treatment was reduced to 162.13 after the treatment with $4.81 \%$ changes and there is statistically significant $(\mathrm{P}<0.05)$. the drugs in the formulation possess anti-diabetic effects through their anti-oxidant and free radical scavenging properties.

In group-B PPBS statistical analysis showed that the mean score which was 169.47 before was increased to 170.07 with $0.35 \%$ decrement.

\section{RBS- Random blood sugar}

In Group-A RBS showed that the mean score which was 154.6 before the treatment was reduced to 144.87 after the treatment with $6.29 \%$ changes and there is statistically significant $(\mathrm{P}<0.05)$. The medicine has given a hypo-glycemic action, thus helping in lowering the fasting blood sugar levels.

In Group-B RBS showed that the mean score which was 154.53 before it was increased to 155.87 with $0.87 \%$ changes and there is statistically significant $(\mathrm{P}<0.05)$

\section{CONCLUSION}

Diabetes mellitus is one of the oldest diseases recognized since antiquity. It is a silently killing disease that has affected millions. Recently, the concept of prediabetes has been co-related by the modern science for the purpose of prevention. Many research works are carried out on Diabetes Mellitus but very less on Pre-diabetes. People with pre-diabetes have an increased risk of getting Type-2 Diabetes Mellitus. Pre-diabetes is now recognized as a reversible condition with certain dietary and lifestyle modifications.

The lakshanas told in classics and the symptoms told in recently co-related pre-diabetes is almost same. Pathya is the base for treating Diabetes Mellitus. Pathya should be emphasized when dealing with the management of Diabetes Mellitus. In present study, Pathya dravyas like Amalaki, Haridra and Madhu were selected and it provided significant results.

The formulation helped in overcoming the symptoms of pre-diabetes 
especially fatigue, increased thirst and hunger. The group which was not administered with any medicine did not have any improvements and there is a definite chance of developing diabetes mellitus. They also showed signs of developing diabetes mellitus. So the Pathya dravyas Haridra, Amalaki and Madhu intake should be practiced regularly to prevent diabetes.

The present study was conducted with limited time, limited facilities and limited number of patients. A study of larger group may help to comprehend the mode of action of the trial drug.

A further study with strict dietary intervention and specific lifestyle modifications is recommended. In the future, additional studies may be performed to take the present issue further in a proper perspective and future possibilities of reduction of modern drug requirement or relaxation of dietary restriction.

Acknowledgement: None

Conflict of Interest: None

Source of Funding: None

\section{Ethical Approval: Approved}

\section{REFERENCES}

1. Text book of medicine by K.V Krishna Das $5^{\text {th }}$ edition, Jaypee Brothers medical publishers (P) LTD, New Delhi, pg,no 544

2. https://www.idf.org/aboutdiabetes/what-isdiabetes

3. https://ncbi.nlm.nih.gov/pmc/articles/PMC5 792082

4. Park's Textbook of Preventive and Social Medicine, $19^{\mathrm{TH}}$ Edition, M/S Banarasidas Bhanot publishers, Jabalpur, 482001(INDIA), pg.no, 328

5. https://www.webmed.com/diabetesguide/whatisprediabetes

6. Gulabani M, John M, Issac R. knowledge of diabetes, its treatment and complications amongst Diabetic patients in a tertiary care hospital, Indian journal of community medicine 2008; 33(3): 204-6

7. Park's Textbook of Preventive and Social Medicine, $19^{\mathrm{TH}}$ Edition, M/S Banarasidas Bhanot publishers, Jabalpur, 482001 (INDIA), pg no, 456

How to cite this article: Somayaji SM. A clinical study to evaluate the preventive aspect of amalaki swarasa and haridra churna with madhu in pre-diabetes (borderline type2 DM). Int $J$ Health Sci Res. 2021; 11(8): 67-78. DOI: https://doi.org/10.52403/ijhsr.20210810 